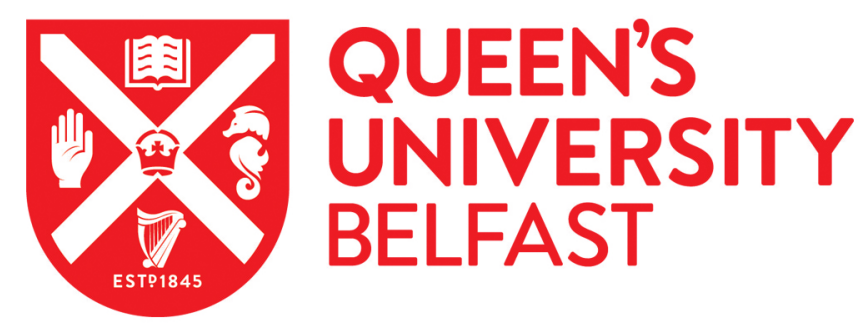

\title{
Pull-out behaviour of axially loaded Basalt Fibre Reinforced Polymer (BFRP) rods bonded perpendicular to the grain of glulam elements
}

Yeboah, D., Taylor, S., McPolin, D., \& Gilfillan, R. (2013). Pull-out behaviour of axially loaded Basalt Fibre Reinforced Polymer (BFRP) rods bonded perpendicular to the grain of glulam elements. Construction and Building Materials, 38, 962-969. https://doi.org/10.1016/j.conbuildmat.2012.09.014

Published in:

Construction and Building Materials

Document Version:

Early version, also known as pre-print

Queen's University Belfast - Research Portal:

Link to publication record in Queen's University Belfast Research Portal

Publisher rights

(C) 2013 The Author

\section{General rights}

Copyright for the publications made accessible via the Queen's University Belfast Research Portal is retained by the author(s) and / or other copyright owners and it is a condition of accessing these publications that users recognise and abide by the legal requirements associated with these rights.

Take down policy

The Research Portal is Queen's institutional repository that provides access to Queen's research output. Every effort has been made to ensure that content in the Research Portal does not infringe any person's rights, or applicable UK laws. If you discover content in the Research Portal that you believe breaches copyright or violates any law, please contact openaccess@qub.ac.uk. 


\section{BACKGROUND}

Connections with bonded-in steel or fibre reinforced plastics (FRPs) offer improvements over the traditional type of jointing which include higher load transfer, improvement in aesthetic properties, good fire resistance (since the connection is completely hidden in the insulated timber elements) and higher stiff connections. The rods are placed into oversized holes and the cavity is filled with an adhesive to enable the adhesive to bond the rods to the timber, thereby enabling transfer of load from the timber elements to the connecting rod.

Several researchers, including Kangas [1] and Riberholt [2] have investigated the potential of bonded-in rod technique for a range of new-build applications including connection of glulam beams. These joints are also used to repair the decayed parts of timber structures by splicing on new timber or upgrading of existing timber structures that have been deteriorated [3]. Bonded-in rods are also used to prevent end-cracks in the apex zone of curved beams and in end-notched beams; to transfer forces between structural elements as in a frame corner; to transfer forces into a structure, or part of a structure, as in a column foundation joint [4]. Ansell and Smedley [3] reported that Tourand Creek Bridge in Canadian bridge was upgraded by bonding CFRP reinforcement into the upper and lower faces of beams. Bonded-in rod technique was also used in the glulam dome structure of the Sydney 2000 Olympic Games [5].

The influence of geometrical and material properties on the capacity and behaviour of bonded-in rods was investigated by Mettem [6]. Serrano [7] used a strain-softening crack model to characterize the behaviour of the adhesive layer between the steel rods and the timber elements of bonded-in rod connections. Alam et al [8] researched on repair of fractured C16 spruce beams using steel as reinforcement materials. They found that steel repairs were shown to improve the stiffness and strength of a broken spruce beam by up to $114 \%$ and $255 \%$ respectively of its original stiffness and strength values. Yeboah et al [9] fabricated and tested portal joints and observed that the performance of the joint depended on the strength of timber adjacent to the tension rods.

Timber used for connections with bonded-in rod joints is mostly glulam made from softwood. This is because the quality and reliability requirements of glulam have contributed to make it a competitive alternative, both in terms of cost and performance, to traditional structural materials (reinforced concrete and steel), promoting its use in large structural components [4].

Adhesives such as epoxy, polyurethane and phenol resorcinol have been used as binding agents to connect the timber members. Epoxy adhesives are currently the most accepted adhesive type for bonded-in rod joints since they do not require high pressure during their application and curing and are reasonably tolerant with regard to bondline thickness variations. They also exhibit strong adhesion to several materials, little or no shrinkage during cure, dimensional stability after hardening, excellent mechanical resistance and high resistance to chemical products and water [10]. The other adhesives namely phenol-resorcinol-formaldehyde (PRF), acrylic and polyurethane (PUR) have limited gap-filling properties and also show poor joint capacities producing cohesive adhesive failures in most cases [4]. 
In the past two decades, the use of fibre reinforced polymers (FRPs) as alternative connecting rod in timber structures has increased as a result of several advantages these materials possess compared to other conventional materials such as steel. The strength and stiffness of FRPs are significantly high in relation to their weights compared to steel. FRPs also limit heat transmission during fire outbreak and low transportation costs [11]. Raftery and Harte [12] investigated the use of glass fibre reinforced polymer (GFRP) plates in timber beams and reported that GFRP reinforcement offered significant improvement in the ultimate moment capacity of the low-grade glulam beams. Micelli et al [11] conducted an experiment on reinforcement of carbon fibre reinforced polymer (CFRP) rods in glulam beams and recorded moment capacity of up to 93\% of the unreinforced beams. Recently, Yeboah et al [13] have also investigated the capacity of bondedin BFRP rod timber beams and reported that, BFRP rods are potential resource for reinforcement in timber structures.

A new type of FRP made from basalt fibre (BFRP) has good potential to provide benefits that are comparable or superior to GFRP, and significantly cost effective compared to CFRP. However, investigation into the use of BFRP rods as reinforcement materials in timber structures is very limited. Initial investigation on the use of BFRP as connecting rod by Yeboah et al [13] considered samples loaded parallel to the grain. In this study, an experimental programme was conducted to investigate the behaviour of bonded-in BFRP rods loaded perpendicular to the grain of glulam members. The main aim of the present research was to examine the effect of bonded length and bond stress-slip on the structural capacity of the connections and to propose an analytical expression to predict bond strength for the design of timber beams.

\subsection{THEORETICAL BACKGROUND}

\subsubsection{Loading configurations}

Serrano et al [14] identified four different types of fabrication and loading configurations for pullout tests. These are pull-pull, pull-compression, pull-beam and pull-pile foundation configurations. Pull-pull and pull-compression conditions are used mainly for both parallel and perpendicular to the grain tests, whereas pull-pile foundation and pull-beam situations are suitable for perpendicular to the grain tests. [6]. Gustafsson et al [15] observed that the pull-pull type of loading is more representative and produces higher pull-out strengths. However, it is more expensive than the pullcompression type since more materials and fabrication processes are needed. Pull-beam situation is not really practical and inefficient for testing because a large amount of timber would be required and the pull-out capacity could be influenced by bending stresses in the beam [16]. Pull-pile foundation configurations prevent crushing of wood and tension failures perpendicular the grain [16]. However, this type of pull-out set up is expensive as more rods would be needed for the fabrication of the samples. Windmann et al [16] have stated that loading the pull-out test specimens in pull-compression configuration does not correspond to practical situations and there is likelihood of local excessive compression stresses perpendicular to the grain in the area of the load application. This in particular is more likely only if the hole through which pulling is done is small.

\subsubsection{Failure mechanisms}


Two major failure mechanisms associated with bonded-in rod connections loaded perpendicular to the grain are:

- longitudinal timber shear around the hole, with non-uniform thickness;

- longitudinal timber splitting

Shear fracture of timber close to the joint is the most frequent failure mode. This failure mechanism occurred when the shear capacity of the timber was exceeded [4]. Broughton and Hutchinson [4] also reported that, optimal bond capacity is reached when shear failure of timber occurs. Longitudinal timber splitting results from tensile failure in the timber perpendicular to the grain as a result of low tensile strength perpendicular to grain or low edge distance [15].

\subsubsection{Minimum spacings and bonded lengths}

Minimum bonded length $l_{a, \min }$ for perpendicular to the grain samples according to ENV 1995-2 [17] is as follows:

$l_{a, \min }=\max \left\{\begin{array}{c}0,5 d^{2} \\ 10 d\end{array} \quad\right.$ (1), where $d$ is the diameter of the rod.

These spacings are specified to reduce splitting of the timber and to maximise the load transfer efficiency of the connecting rod. The ENV 1995-2 [17] recommended a minimum edge distance of $2.5 d$.

\section{EXPERIMENTAL PROGRAMME}

Material properties (Table 1) of timber are based upon tests on control samples carried out in accordance with [17] whereas those of BFRP rods were by direct tensile testing.

\subsection{Timber}

Timber used for the tests was sourced from spruce (Picea albies) glulam elements (90 mm x 270 $\mathrm{mm}$ ) made of $45 \mathrm{~mm}$ thick (see Table 1 for measured properties). The laminates were end-jointed and then glued together by melamine adhesives at ambient environmental conditions. Glulam was used for this experiment because the mechanical properties are more uniform and also defects such as knots are spread through the layers of the members thus reducing material variability. The choice of the glulam elements also depended on their availability at the market.

\subsection{Basalt Fibre Reinforced Polymer (BFRP) rods}

Basalt fibre reinforced polymers (BFRP) rods are inorganic fibre materials extruded from volcanic basalt rock deposits (an inert rock formed by the solidification of molten lava) in a single-melt process. The process technology is extremely similar to that used for glass fibres. The rock is first pre-treated and then melted to obtain continuous fibres. The melt flows into one or more bushings containing hundreds of small orifices. The basalt filaments formed as the molten rock passes through these orifices. The filaments are then pulled over a roller in the pultrusion process to form 
the FRP rod. It is mainly used in construction, industrial and high way engineering. BFRP can also be used to reinforce a new range of (plastic and concrete matrix) composites. They were chosen as the reinforcement materials for this experiment due to their high strength, low weight, corrosion resistant and cost performance (less expensive alternative to carbon fibres) [19].

The tensile strength of the rods was assessed using direct tensile testing machine with special end fixing to prevent crushing of the fibres at the ends. Figure 1 shows the tensile rupture of BFRP rods. The tensile strengths were lower than that reported by the manufacturer (Table 1) due to a lower loading rate which was more appropriate for timber beam loading.

In order to ensure centralisation of the rods in the holes and hence uniform annular bondline thickness, one end of each rod (that enters the timber block) was tapered in a lathe (Figure 2a) to match the end profile of the bit used for drilling. The other end of each rod to which the pull-out load had to be applied was coated with epoxy resins (Figure 2b) and was allowed to cure for 24 hours before bonding, to enhance gripping.

\subsection{Adhesive}

A 2-part epoxy gap filling (thickness $2 \mathrm{~mm}-12 \mathrm{~mm}$ ) adhesive (from Rotafix) was used for the experiment. Epoxy adhesives consist of two components and one of them is the base which contains an epoxy resin, including additives. The second component is the curing agent or hardener. They are thixotropic, such that, they flow when sheared but remain static when the shear force is removed. Generally epoxy develops a strong bond with the connecting rod and the timber, resulting in the timber becoming the weakest link of the joint [19]. Epoxy resins are capable of reacting with suitable hardeners to form cross-linked matrices of great strength and with excellent adhesion to a wide range of adherends. This makes them ideally suited to adhesive applications in which strength under adverse conditions is a requirement [20]. Their unique characteristics include negligible shrinkage during cure, an open time equal to the usable life, excellent chemical resistance, ability to bond nonporous adherends and great versatility. Stumes [21] reported that the shear strength of epoxy resins is two to three times that of timber. The 2-part thixotropic epoxy resin was mixed according to the manufacturers specifications. One part resin base container $(330 \mathrm{~g})$ was mixed with one part hardener $(145 \mathrm{~g})$ in a ratio of 1:0.4 respectively. The base and hardener were mixed thoroughly until the desired viscosity was just enough so as to allow for easy application.

\subsection{Preparation and fabrication samples}

Table 2 illustrates test variables used for the tests. Following the recommendations by [22], the moisture content of the timber blocks for this experiment was determined by the oven-drying method. The moisture content of the timber samples at the time of bonding ranged from 8-10\% as based on recommendations by [4] who showed that moisture contents appropriate to Service Classes 1 and 2 as defined by [17] (i.e. up to 20\%) can be bonded without any concern over loss of joint integrity. Shrinkage and swelling due to changes in moisture content may cause considerable shear stresses in the bondline. If the moisture content of the timber during bonding is much higher than in service, cracks occur at the ends of the rod thus control of moisture content is critical to ensure robust joint [23]. 
Two holes of $16 \mathrm{~mm}$ diameter, with variable lengths to suit the bonded lengths, were drilled perpendicular to the grain of each timber member using a vertical drill. This made efficient use of the timber and also provided the most effective spacings as recommended by [17]. Following the EC5 recommendations (equation (1)), the minimum bonded length was $100 \mathrm{~mm}$ and each bonded length differed from the nearest by $50 \mathrm{~mm}$. The cross sectional dimension allowed for maximum of $270 \mathrm{~mm}$ bonded lengths for the specimens. The drilled holes produced adhesive interface of 2 mm between the BFRP rods and the timber as recommended by [24] who found that for epoxybonded joints a minimum bondline thickness of $2 \mathrm{~mm}$ gave the best bond. Medium density fibreboards were used to seal one end of each block of the $270 \mathrm{~mm}$ samples to prevent the loss of the epoxy adhesive during bonding. In accordance with BS ENV: 1995 [17], the end and edge distances for each specimen were $3.75 d$ and $5 d$. The epoxy adhesive was applied by back-filling to approximately $1 / 3$ of the length of the oversized holes, using an application gun fitted with a microbore tube to achieve effective and uniform application of the resins through the length of the holes. The BFRP rods were then inserted in the partially resin-filled holes slowly and twisted until they reached the bottom of the hole to ensure good coverage and to expel any trapped air which might affect the strength of the joint. Each specimen was identified by direction of load to the grain direction, bonded length, rod diameter and sample number. The specimens were left to cure for six days at $20^{\circ} \mathrm{C}$ to ensure maximum bond strength prior to testing.

\subsection{Test instrumentation and procedure}

The geometry of pull-out specimen and the experimental setup used for the tests are shown in Figure 3 and Figure 4 respectively. Samples were tested in pull-compression type of loading (chosen due to common practice which provides an economy performance, fabrication process and laboratory conditions) in direct tension testing machine fitted with a $100 \mathrm{kN}$ load cell. A pullthrough hole of $38 \mathrm{~mm}$ was machined out of a $127 \mathrm{~mm}$ x $127 \mathrm{~mm}$ square metal base plate to keep the timber section in position and load was applied to the top of the rod. The samples were loaded incrementally to failure.

The load was applied in tension (see Figure 4) and the square base plate in conjunction with the two T-section arrangements, provided reaction (compression) against the specimen as the steel rod was pulled through the pull-through hole at a constant cross-head displacement of $3 \mathrm{~mm} / \mathrm{min}$. The failure load $(\mathrm{kN})$ for each test was recorded when there was total separation of the bond line with zero loadbearing capacity. The average shear stress (bond stress) for each variable at timber/adhesive was calculated by dividing the failure load by the bond area at the interface. The failure mode of each test was also observed and recorded. The percentage failure mode was deduced as the ratio of a particular failure mode to the total number of failure mode (of the nine samples) for that bonded length. Each test was repeated nine times. The local displacement (slip) between the loaded-end of the rod and the timber blocks along the load direction was measured for three of the nine samples for each bonded length. The Linear Variable Differential Transformer (LVDT) connected to data acquisition systems was fixed at a distance (Figure 4), by means of an aluminium rod that was attached to the BFRP rods. As the BFRP rod pulled out, the resulting bond slip was monitored at each increment of load $(1 \mathrm{kN})$ by means of data acquisition connected to the LVDT. The loadedend slip was deduced from the elongation of the distance $\boldsymbol{x}$ portion of the BFRP rod (Figure 5) subtracted from the total deflection read from the LVDT computer. 


\section{RESULTS AND DISCUSSIONS}

Results of the pull-out tests are presented in Table 3 and Figure 6 in terms of failure modes. Figure 7 also shows relationship between failure load and bonded length. Figure 8 represents bond stress versus slip percent responses of the samples tested. The slip percentage of each sample configuration was deduced as the ratio of loaded end deformation to the corresponding bonded length.

\subsection{Failure mechanisms}

Failure mechanisms of the samples were visually estimated and calculated in percentages (Table 3) in accordance with EN ISO 10365 [25]. The results show that there were basically two failure modes recorded for the samples loaded perpendicular to the grain which were shear failure and timber splitting (Figure 6).

Table 3 shows that failure mode of the samples was predominantly interfacial shear at the timber/adhesive zone. The BFRP rods that debonded from the host timber were surrounded by the adhesive layer, keeping small adjacent of wooden fibres ( $<3 \mathrm{~mm}$ from the adhesive interface) attached. As the samples were axially loaded, timber fracture close to the joints initiated the failure mode.

Shear failure of timber occurred since the BFRP rod, epoxy resins and the epoxy/rod interface had higher shear capacity than the host timber. No failure was observed at the rod/adhesive interface or within the adhesive, showing excellent joint performance between the epoxy resins and the BFRP rods. Failure of the samples always started at the timber/adhesive interface - independent of the bonded length - with thin film of attached to the glue. The timber/adhesive shear fracture for the perpendicular to the grain was gradual, due to crushing of the cells. The next stage of mode of failure was timber splitting, as the loading continued, which occurred at higher load capacity. Splitting failures was visible at pull-out load of approximately $40 \mathrm{kN}$. Table 2 showed that the splitting of timber increased with increasing bonded length. Splitting failure was caused by tensile forces in the timber perpendicular to the planes, which was easily cleaved as a result of low tensile strength perpendicular to fibres of the glulam timber elements [26]. Splitting failure resulted in lower performance since the resistance of the timber blocks to pull-out force of the BFRP rod was reduced. The last stage of the sequence of failure for the samples was pull-out of the rods (which was explosive) when there was total separation of timber fibres with zero-load bearing capacity.

\subsection{Bonded length}

Pull-out capacity of the $12 \mathrm{~mm}$ BFRP rods bonded in the glulam elements increased with increase in bonded lengths up to $250 \mathrm{~mm}$ bonded lengths as shown in Figure 7. Between $100 \mathrm{~mm}$ and 250 $\mathrm{mm}$ bonded lengths, the pull-out capacity of the BFRP rods bonded into the glulam timber elements showed approximately linear correlation with bonded lengths. This was mainly due to increased bonded area at the timber/adhesive zone which led to decrease in interfacial shear stress.

Between $100 \mathrm{~mm}$ and $250 \mathrm{~mm}$ bonded lengths the samples recorded improvement of pull-out capacity by $57 \%$. Beyond $250 \mathrm{~mm}$ bonded length the average pull-out capacity slightly decreased as a result of increase in timber splitting failures and also interfacial timber/adhesive strain reaching almost zero at this depth. Consequently the bond does not become active at lengths greater 
than $250 \mathrm{~mm}$ ( 15 times the hole diameter). Thus, the ultimate bonded length for the samples was $250 \mathrm{~mm}$ since there was no significant improvement in joint strength beyond this bonded length. This observation was confirmed by earlier investigations by Yeboah et al [5] who reported that increments of failure load for bonded length greater than about fifteen times hole diameters are insignificant. The tests therefore show that the ultimate bonded length for the design of timber structures such as portal connections with $12 \mathrm{~mm}$ diameter BFRP rods loaded perpendicular to the grain is $250 \mathrm{~mm}$. For rod diameter higher than $12 \mathrm{~mm}$, higher pull-out capacity would be expected at the same bonded length and ultimate bonded length. However, higher rod diameter would mean higher hole diameter which will reduce the end distance therefore splitting failure is more likely to occur at higher bonded lengths.

\subsection{Stress-slip behaviour}

The stress-slip graph (Figure 8) showed that increasing bonded length resulted in corresponding increase in joint slip. Figure 8 also showed that as the bonded length increased stiffness of the samples decreased. The samples exhibited three distinct behaviours (during testing) consisting of ascending and softening (descending) for the pre- and post-peak bond respectively. At the early stages of loading, Figure 8 showed that samples loaded perpendicular to the grain generally exhibited linear stress-slip response. The first stage of the specimens was composed of a steep ascending portion (especially $100 \mathrm{~mm}$ and $250 \mathrm{~mm}$ samples) due to the stiff behaviour of chemical adhesion and friction between the adhesive component and the adherends.

As the stress was increased the stress-slip graph exhibited yielding which might due to propagation of internal fracture at the timber/adhesive interface and gradual pull-out of the BFRP rod. Between $100 \mathrm{~mm}$ and $200 \mathrm{~mm}$ bonded lengths there was sudden drop of load after maximum stress was reached which might be due to end-grain splitting. In the case of higher bonded lengths ( $250 \mathrm{~mm}$ and $270 \mathrm{~mm}$ ), the softening was followed by a gradual non-linear behaviour with an increase in strength, at critical pull-out load of about $40 \mathrm{kN}$ where longitudinal splitting is visible. The stress increased with an increase in slip beyond the critical load. The second stage of the response was characterised by post-peak pseudo-ductile behaviour and sudden drop of bond resistance as the slip increased until final zero stress-bearing capacity.

\section{ANALYTICAL MODELS}

Experimental results obtained by using $12 \mathrm{~mm}$ BFRP rods bonded perpendicular into timber elements were used to validate some notable design equations previously proposed by some authors.

\subsection{Pull-out load and bonded length relationship}

This section deals with prediction of pull-out capacity for the samples at different bonded lengths, using Riberholt [2], BS ENV: 1995-1 [17] and DIN: 1052-12 [27] design approaches.

\subsubsection{Riberholt (1988) design model}


The design code proposed by [2] was expressed in terms of two different cases, one for short bonded lengths, which was a linear relation, and one for longer bonded lengths, which included a square root relation. Thus:

$$
\begin{array}{ll}
P_{u, v, k}=f_{w s} \cdot d \rho_{k} \sqrt{ } l_{b} & \text { for } l_{b} \geq 200 \mathrm{~mm} \\
P_{u, v, k}=f_{w s} \cdot d \cdot \rho_{k} \cdot l_{b} & \text { for } l_{b}<200 \mathrm{~mm}
\end{array}
$$

where $d=\min \left[d_{r}, d_{h}\right]$. The strength parameters $f_{w s}$ and $f_{w l}$ are given as $520 \mathrm{~N} / \mathrm{mm}^{1.5}$ and $37 \mathrm{~N} / \mathrm{mm}^{2}$ respectively for epoxy [13]. Riberhot [2] model was derived on a purely empirical basis by curve fitting of the experimental results.

\subsubsection{BS ENV:1995-2 (1997) design model}

The basic expression for the pull-out of a single rod glued parallel or perpendicular to the grain proposed by BS ENV 1995-2 [17] is according to:

$P_{u, v, k}=f_{v, k} \cdot \pi \cdot d_{e q u} \cdot l_{b} \quad$.

The equivalent diameter of the rod;

$d_{\text {equ }}=\min \left\{d_{h}, 1.25 d\right\}$

$l_{b}=$ bonded length; $f_{v, k}$ representing the characteristic shear strength of the timber around the hole for softwoods for all angles between the rod and the fibre direction, and $d_{r}$ is the rod diameter.

$f_{v, k}=1.2 \times 10^{-3} \times \mathrm{d}_{e q u}{ }^{-0.2} \rho_{k}{ }^{1.5}$

$\rho_{k}$ is the characteristic density of the timber members $\left(\mathrm{kg} / \mathrm{m}^{3}\right)$.

For threaded rods, $d=d_{\text {nom }}$ and for deformed rods, $d=1.1 d_{\text {nom }}$ where $d_{\text {nom }}$ is the nominal rod diameter.

\subsubsection{DIN: 1052-12 (2008) design model}

The German design code, DIN: 1052-12 [27] proposed for axially loaded rods bonded-in parallel or perpendicular to the grain is according to:

$P_{u, v, k}=\pi \cdot d \cdot l_{b} f_{v, k}$

According to the model, $f_{\mathrm{v}, k}$ depends on the bonded length and is derived from the relations below. $f_{\mathrm{v}, k}=4.0$ for $l_{b} \leq 250 \mathrm{~mm}$

$f_{\mathrm{v}, k}=5.245$ for $250<l_{b} \leq 500 \mathrm{~mm}$

$f_{\mathrm{v}, k}=3.499$ for $500<l_{b} \leq 1000 \mathrm{~mm}$ 


\subsubsection{Proposed Design Model}

The proposed design model is a based on the shear fracture in the timber close to the bond (i.e. < $3 \mathrm{~mm}$ ) at the timber/adhesive interface with peak failure load at the $250 \mathrm{~mm}$ bonded length. As discussed previously, beyond the ultimate bonded length there was no significant joint improvement. It also takes into account the ratio of bonded length to hole diameter which is about 15. The mean pull-out capacity, $P_{u, \text { mean }, k}$, of the proposed design approach is as follows:

$P_{u, \text { mean }, k}=\pi \cdot f_{v, \text { mean }} \cdot d_{h} \cdot l_{b}$

where, $f_{v, \text { mean }}=5.7 \mathrm{~N} / \mathrm{mm}^{2}$

For $l_{b}>15 d_{h}, l_{b}=15 d_{h}$

\subsubsection{Comparison of experimental and theoretical pull-out capacities}

Figure 9 shows results of experimental and theoretical bond strength for $12 \mathrm{~mm}$ BFRP rods loaded perpendicular to the timber blocks. The DIN: 1052-12 [27] design model recorded the lowest bond strength up to $250 \mathrm{~mm}$ bonded length, which was due to lower shear strength used used in developing the model. According DIN: 1052-12 [27] design proposal, pull-out capacity significantly increased beyond $250 \mathrm{~mm}$ bonded length which was inconsistent with the test results. According to Figure 9, it was unsafe to use BS ENV 1995-2 [17] model to design bonded-in BFRP samples loaded perpendicular to the grain since the model predicted no upper limit of bonded length for the design of the timber joints. The pull-out capacity derived from BS ENV 1995-2 [17] considerably exceeded the average values of the test results beyond $150 \mathrm{~mm}$ bonded length as a result of overdependence of bond shear strength on timber density. Researchers have varied opinions on the influence of density on bonded-in rod joints. Bernasconi [28] reported that, density had a poor correlation with joint strength, whereas Serrano [7] assumes it does influence the pullout capacity.

The design pull-out capacities of samples loaded perpendicular to the grain at $200 \mathrm{~mm}$ bonded length for Riberholt [2] equation was $40 \%$ lower than the mean capacity from the tests. The joint capacity of perpendicular to the grain samples proposed by Riberholt [2] at $250 \mathrm{~mm}$ bonded length was 30\%. Riberholt's proposal showed bi-linear curve between $100-200 \mathrm{~mm}$ and $200-270 \mathrm{~mm}$ bonded lengths. According to Riberholt [2], a very long bonded length has little influence on the joint strength, which was also established by the test results. The proposed design equation by Yeboah et al [13] was developed for parallel to the grain samples but works for perpendicular to the grain samples. Figure 9 showed that the proposed design model recorded the most consistent pull-out values with the test results. It clearly showed almost linear increase of pull-out capacity up to $250 \mathrm{~mm}$ bonded length. According to Yeboah et al [13] proposal joint strength improvement was insignificant beyond $250 \mathrm{~mm}$, which was also confirmed by the experiment.

\subsection{Bond stress-slip response of the pull-out samples}

The bond stress-slip response of the reinforced bonded-in BRFP rod joints were analytically described by means of some established design models used in reinforced concrete structures to investigate the distribution of interfacial stresses at the timber/adhesive zone. The Eligehausen, 
Popov and Bertero (EPB) [29] model developed for steel reinforcements which has been successfully used in FRP reinforcements was applied (Figure 10). The model expresses the ascending branch of the bond-slip $\left(\delta \leq \delta_{m}\right)$ relationship as:

$$
\tau / \tau_{m}=\left(\delta / \delta_{m}\right)^{\alpha}
$$

According to Eligehausen et al [29], the parameter $\alpha$ was evaluated by equating the area $A \tau_{1}$ underneath the ascending branch of the curve as:

$A_{\tau_{m}}=\int_{0}^{\delta_{m}} \tau(\delta) \cdot d \delta=\int_{0}^{\delta_{m}} \tau_{m}\left(\delta / \delta_{m}\right)^{\alpha} \cdot d \delta=\left(\tau_{m} \delta_{m}\right) /(1+\alpha)$

From (13), $\alpha=\tau_{m \cdot} s_{m} / A_{\tau_{m}}-1$

The second branch (descending portion), according to the model, covering $\left(\delta_{m}, \tau_{m}\right)$ to $\left(\delta_{3}, \tau_{3}\right)$ is also expressed as

$$
\tau / \tau_{m}=1-\forall\left(\delta / \delta_{m}-1\right)
$$

The portion of the curve $\delta>\delta_{3}$ is a horizontal branch that depicts $\tau_{3}$. The unknown parameter, $\alpha$, obtained by best fitting of the experimental results was 0.50 . The results of the bond stress-slip response for the experimental results on the $100 \mathrm{~mm}$ bonded length and the modified BPE model are shown in Figure 11.

Figure 11 shows that, the EPB model gave a good correlation of the bond stress-slip behaviour of bonded-in BFRP rod joints loaded perpendicular to the grain up to maximum load. At the ascending branch of the curve, the model slightly underestimated the bond stress. At the initial descending branch, (that is, failure path of the loading process) it is also observed that the EPB theory predicted the bond stress with good accuracy. However, the experimental curve showed non-linear behaviour just before the final separation of the bond, which may have been due to internal fracture, such as splitting.

\section{CONCLUSIONS}

The main findings of the behaviour of BFRP rods bonded perpendicular to the grain is summarised in this section. It was found that pull-out capacity increased almost linearly with the bonded length up to maximum which occurred at a bonded length of 15 times the hole diameter and did not increase beyond this bonded length. Thus, $250 \mathrm{~mm}$ was the ultimate bonded length for design of timber structures with $12 \mathrm{~mm}$ BFRP rods.

It was also observed that, the most significant failure modes was shear fracture which occurred at the timber/adhesive interface and pull-out of the BFRP rods showing excellent bond between the rod and the epoxy glue. The BFRP rods that debonded from the host timber were surrounded by the adhesive layer, keeping small adjacent of wooden fibres. 
The BS ENV:1995-2 (1997) and DIN: 1052-12 (2008) design were unsafe for design of bondedin BFRP joints whereas Riberholt design model was safer means of predicting the strength of bonded-in rod joints. However, the proposed design model gave the most accurate prediction of pull-out capacity, showing that there was no increase in joint strength at bonded lengths beyond 15 times the hole diameter.

It was found that, the samples exhibited double branch behaviour consisting of ascending (brittle) and softening (pseudo-ductile) behaviour for the pre- and post-peak bond respectively. The distribution of stress at the timber/adhesive interface of the samples was non-linear and increasing bonded lengths resulted in increase in joint slip. The results also showed that the EPB model was in good agreement with the bond stress-slip behaviour of bonded-in BFRP rod joints.

It can be concluded that, results of these tests and the proposed model may serve as a useful reference for future design of bonded-in rod joints.

\section{ACKNOWLEDGEMENTS}

The authors acknowledge the School of Planning, Architecture and Civil Engineering at Queen's University Belfast for sponsoring the research. The authors are also grateful to Magmatech Ltd for the supply of the basalt rods.

\section{NOTATION}

$\begin{array}{ll}l_{b} & \text { Bonded length } \\ \tau_{f} & \text { Shear resistance of glueline } \\ E_{r} & \text { Young modulus of the rod } \\ t_{r} & \text { Rod thickness } \\ G_{f} & \text { Total fracture energy } \\ \lambda & \text { Brittleness ratio } \\ d & \text { Outer diameter of the rod } \\ \rho & \text { Relative density of timber (derived from oven dry mass and volume in humid } \\ d_{h} & \text { conditions, i.e. 12 \%) } \\ d_{\text {equ }} & \text { Hole diameter } \\ f_{v, k} & \text { Equivalent rod diameter } \\ f_{v, \text { mean }} & \text { Characteristic shear strength } \\ P_{u, v, k} & \text { Mean shear strength determined experimentally } \\ P_{u, \text { mean, }} & \text { Characteristic pull-out load } \\ \tau & \text { Proposed mean pull-out load } \\ \delta & \text { Local bond stress } \\ \tau_{m} & \text { Local slip } \\ \delta_{m} & \text { Peak stress } \\ \delta_{3} & \text { Slip at peak } \\ \alpha & \text { Slip at the softening branch } \\ \tau_{3} & \text { Constant that must not be greater than } 1 \\ & \text { Friction component }\end{array}$


$\forall \quad$ Parameter accounting for the softening branch of BPE curve

$A \tau_{1} \quad$ Area under the ascending branch of BPE curve

\section{REFERENCES}

[1] Kangas J. Joints of glulam structures based on glued-in ribbed steel. VTT Publications, 196, 1994, Espoo.

[2] Riberholt H. Glued bolts in glulam-proposals for CIB code. Proceedings of the 21st conference of CIB-W18, Parksville, Canada.

[3] Ansell M. P. and Smedley D. Bonded-in technology for structural timber. Proceedings of the ICE - Construction Material, Vol., 160, Issue 3, 2007, p 95 - 98.

[4] Broughton J. G. and Hutchinson A. R. Adhesive systems for structural connections in timber. Int. Journal of Adhesives \& Adhesion, 21, 2001, p 177-186.

[5] New Zealand (NZ) Information Sheet. Structural connections - Epoxy grouted steel rods design data. 2007.

[6] Mettem C.J., Bainbridge R.J., Broughton J.G., Hutchinson A.R. Evaluation of Material combinations for bonded-in rods to achieve improved timber connections. CIB-W18 Meeting Thirty-two, Graz Austria, 1999, p 1-13.

[7] Serrano E. Glued-in rods for timber structures-an experimental study of softening behaviour. Materials and Structures 34, 2001, p 228-234.

[8] Alam P., Ansell M. P., and Smedley D. 2010. Mechanical repair of timber beams fractured in flexure using bonded-in reinforcements. Composites: Part B 40, Elsevier, pp 95-106.

[9] Yeboah D., S. Taylor, D. McPolin, Gilbert S. and Gilfillan R. Behaviour of joints with bondedin steel rods loaded parallel to the grain of timber elements. Const. and Building Mat., 25, 2011, p 2312-2317.

[10] Thelandersson S and Larsen H. J. Timber Engineering. John Wiley \& Sons Ltd, 2003, p 334353

[11] Micelli P.E.F., Vicenza S.P.E., La Tegola A. Flexural reinforcement of glulam timber beams and joints with carbon fobre-reinforced polymer rods. Journal of Composites for Construction, 2005, pp337 -343.

[12] Raftery G. M. and Harte A. Low-graded glued laminated timber reinforced with FRP plate. Composites: Part B 42, 2011, p 724 - 735. 
[13] Yeboah D., S. Taylor, D. McPolin and Gilfillan R. Pull-out of axially loaded Basalt Fibre Reinforced Polymer (BFRP) rods bonded parallel to the grain of glulam elements. The Structural Engineer, 2012

[14] Serrano E, Steiger R, Lavisci P. Glued-in rods. In: Bonding of timber-core document of the COST Action E34. Lignovisionen, 18, 2008, p 31-39.

[15] Gustafsson P. J., Serrano E., Aicher S. and Johansson C. J. A strength design equation for glued-in rods. Proceedings of the Int. RELEM'S. 22, 2001, p 324 - 327.

[16] Windmann R., Steiger R. and Gehri E. Pull-out strength of axially loaded steel rods bonded in glulam perpendicular to the grain. Materials and Structures. 40, 2007 p 827 - 838.

[17] European Committee for Standardization CEN Eurocode 5-design of timber structuresPart 2: Bridges ENV 1995-2:1997, CEN, Brussels

[18] Tharmarajah G., Taylor S. E., Robinson D. and Cleland D. Composite reinforcement for bridge deck slabs. Queen's University, Belfast, UK, p 2.

[19] Sim J., Park C., Moon D.Y. Characteristics of basalt fibre as a strengthening material for concrete structures. Composites: Part B, 36, 2005, P 504-512.

[20] Tlustochowicz G., Serrano E., and R. Steiger. State-of-the-art on timber connections with steel rods. Materials and Structures, 2010.

[21] Stumes P. Testing the efficiency of wood epoxy reinforcement systems. Association for Preservation Technology, Vol. 7, No. 3, 1975, p 2-35.

[22] BS EN 13183-1. Moisture content of a piece of a sawn timber - Part 1: Determination by oven dry method.

[23] Davis G. Performance of adhesive systems for structural timbers. Int. Journal of Adhesion \& Adhesives, 17, p 1997, 247-296.

[24] Ansell M. P. Harvey K. Improved timber connections using bonded-in GFRP rods, Proc. of $6^{\text {th }}$ WCTE World Conf. in Timber Eng., Whistler, Canada, 2000.

[25] EN ISO 10365. Adhesives - 'Designation of the main failure patterns', 1992.

[26] De Lorenzis L., Scialpi V., La Tegola A. Analytical and experimental study on bonded-in CFRP bars in glulam timber, Composites: Part B, 36, 2005, p 279-289.

[27] Deutsches Institut für DIN: 1052-12 (2008), Berlin

[28] Bernasconi A. Behaviour of axially loaded glued-in rods - requirements and resistance, especially for spruce timber perpendicular to the grain direction, CIB-W18, Timber Structures, Italy, 2001. 
[29] Eligehausen R., Bertero V. V. Popov E. P. Local bond stress-slip relationships of deformed rods under general excitations. Rep No. 82/23, Earthquake Engineering Research Centre, Univ. California, Berkeley, Calif, 1983 